\title{
The Effect of Television Commercials on Customers' Loyalty - A Mediation Analysis of Brand Awareness
}

\author{
Mai Ngoc Khuong, Nguyen Vu Ai Hoa, and Truong Duc Nguyen
}

\begin{abstract}
The main objective of this study was to investigate the effects of television commercials (TVCs) on customers' loyalty through brand awareness in Ho Chi Minh City, Viet Nam. Quantitative approach was applied with structured questionnaires conveniently and directly to 300 customers of milk industry. Several statistical techniques were used such as factor analysis, multiple regressions, and path analysis. This study found that factors of TVCs including music, trust, humor, interest, advertising message, repetition, and length were positively associated with brand awareness and customers' loyalty. The empirical results showed that customers' loyalty was significantly and directly affected by trust, interest, brand recall, and brand recognition. In addition, customers' loyalty was indirectly affected by the factors of repetition, humor, advertising, message, and trust. It was recommended that advertising managers should improve these factors when they decide to advertise theirproducts or services on television to induce customers' brand awareness as well as brand loyalty.
\end{abstract}

Index Terms-Television commercial, customers' loyalty, brand awareness, brand recall, brand recognition.

\section{INTRODUCTION}

Since 1939, when television was first introduced at the New York World's Fair, this device has been used widely as an advertising medium. Television allows marketers to touch a very large audience with ease. Despite the Internet ad's steady rise in popularity over the last few years, advertising on television remains the leading medium for conveying a mass message.

Estimated by the ZenithOptimedia [1], advertisers worldwide spending will grow $4.9 \%$ in 2015 , reaching 545 billion U.S. dollars by the end of the year, and television's share of global advertising spending is $40 \%$. Moreover, recent studies show that on average, the general population spent over four and a half hours a day in front of the tube. That made $\mathrm{TV}$ watching become one of the most common modern leisure activities. On a long-term basis, television advertising will continue to be the most powerful form of advertising.

Television commercials in Viet Nam have continued this trend. According to IFM [2], FTA (Free-to-Air Advertising) represented up to $68 \%$ of total advertising sales of local media. In 2013, TVCs sales extended over 523 million U.S. dollars. By 2015, FTA spending is forecasted to exceed 677 million U.S. dollars. In addition, Kantar Media survey recently

Manuscript received July 20, 2015; revised February 7, 2016.

Mai Ngoc Khuong, Nguyen Vu Ai Hoa, and Truong Duc Nguyen are with the School of Business, International University - VNU-HCM, Vietnam (e-mail: mnkhuong@hcmiu.edu.vn, nvaihoa@gmail.com, truongducnguyen17191@gmail.com). showed that more than $90 \%$ of families having a TV set. This survey also reveal that, Vietnamese spend about 229 minutes watching TV a day, compare with 50 minutes for surfing Internet, and only 16 minutes for reading newspapers [3]. With the largest number of audiences, TV is considered the most powerful advertising tool. It still holds true, of course and now this research provide a more complete view of the role of television commercials in building loyalty, which will enable marketing companies in Viet Nam to leverage positive influences of TVCs.

It is reported that in first nine months of 2013, TV ad sales reached over VND12.5 trillion VND. More specific, TV advertising in 2013 marked a record in terms of prices when a company spent up to VND 280 million to have their product advertised during an ad break from The Voice Kids program on VTV3 for only 30 seconds [4]. It is doubtlessly that advertisers do spend a huge amount of money and effort in generating and broadcasting their advertisements. As a consequence, the companies want to obtain their short-term objectives that introduce product to the customers and raise the product sale as much as they want to achieve their long-term goals that creating and enhancing the customer's loyalty. There appear to be few studies that have investigated the relative and combined influence of television advertisings on customers' loyalty. This research aimed to find out what factors/elements of TVCs induced customers' brand awareness and their loyalty.

\section{LITERATURE REVIEW}

\section{A. Television Commercials}

A commercial television advertisement is a short television program, being widely produced and paid for by a company. Those companies use TVCs as a tool to deliver a message to the community to market and publicize their product(s) and service(s). Apparently, the main commercials' objective of TVCs is show and state what the product is, what its main features are and what advantages it have [5]. Moreover, TV ads can generate demand for products, services in a limited amount of time, encouraging customers to buy things and gain more awareness [6].

The results of Schellenberg's study showed that five different types of television commercials were existed: political advertising, promotional advertising, infomercials, television commercial donut as well as sponsorship advertising [7]. Additionally, television commercial is an essential tool for companies to win in the mass-market advertisement. As long as the companies want to gain attention and interest of the customers, television ads may as well continue to be a hot topic for the researchers. 


\section{B. Repetition}

According to [8], research about the impact of advertisement repetition on attitude based on condition such as motivation, ability, and opportunity, the result showed that there is a significant impact of motivation/ability on repetition. When the repetition of advertisement increases, the brand attitude and purchase intention increases as well.

Moreover, [9] conducted a research on the advertising's impact on purchase intention, message recall in sports arena. The result indicated a positive association between the frequency of advertisement and purchase intention and brand name recall. Specifically, the more advertising increase, the more the purchase intention and brand recall increase.

In the study of [10] investigated about the impact of TV advertisement repetition, celebrity endorsement and perceived quality on consumer purchase decision. The result showed that only advertisement repetition, and perceived quality has a positive significant impact on purchase decision. After watching television commercial many time, the positive image about the product advertised will influenced customer to buy this product.

In the recent study of [11] about the influence that advertisements have on customer loyalty, the researchers discovered that the more customers are frequently exposed to their service provider's advertisement, the more they will become loyal to that particular service.

\section{Humor}

Several authors have extensively researched about the use of humor in advertising. According to [12], the study have found that humorous advertisement messages is not only attract and hold consumers' attention but also increase liking for both the advertisement and the advertised brand. It means that the customers, who were attracted by humorous advertisements, become like the advertisements. Then, audiences will focus more on the advertised brand and product. Finally, customers will think positively, being convincing easily by any information in the television advertise, though for the most fastidious customers.

In the study of [13], researchers examined the moderating effects of product involvement on the effects of humor on memory and attitude towards the advertisement. The result showed that there is a strong connection between humor and memory of advertised product and brand name.

The research of [11] investigated the influence of advertisement on customer loyalty in the telecommunications industry in Ghana. The search argued that the Message content of the service provider's advertisements was the most factor influence customer patronage; this was followed by the humorous nature of the advertisements. Personalities within the advertisement and the background music in case of broadcast advertising were found to be least most significant factor in the advertisements respectively.

\section{Advertising Message}

Various researches have been done to examine how advertising message influences our consumption behavior. According to [14], advertising message was an outstanding point that allows customers to remember the advertisement and induces purchase advertised product within a customer.
Important message usually gain customers' attention easily, rather than a disfavor or irrelevant message. Only by meaningful and related message can the advertisement gain customer attention.

It is good advertising message that make profound contribution to the relationship with effective television commercial and customers' purchase intention. Message content of the advertising not only earn customers' trust but also motivate audiences to concentrate on its content, can also create logical buying intention of a customer [15].

Moreover, the study of [11] stated that advertisement has influence on customer loyalty. The message content, humor, personalities and to some degree background music were all found to persuade some level of interest amongst participants. Among four factors within an advertisement, message content of the service provider's advertising has been found as the most factor influence customers' loyalty.

\section{E. Trust}

Advertisers believe that trust towards the TVCs has a positive impact on enhancing customers' loyalty. According to [16], trust can be divided into four trust constructs. First, trusting belief-competence, describe customers believes that the company has the capacity to deliver the product easily. Then, trusting belief-benevolence, which indicates the customers believes that the company care about them and is inspired to perform in customers' interest. Next, trusting belief-integrity define the situation when buyers totally believes that the sellers makes good faith agreements, tells the truth, acts ethically, and fulfills promises. Finally, trusting belief-predictability, which means customers trusts the company's actions (good or bad) are consistent sufficient compare with what they forecasted.

Reference [17] has studies on trust in relation to advertising. In this research, trust has been conceptualized as "confidence that advertising is a reliable source of product/service information and willingness to act on the basis information conveyed by advertising". Moreover, the researchers have developed a tool specifically for measure "trust value": the ADTRUST scale. This scale incorporated "the seven factors of trust most often identified by scholars: integrity, reliability, benevolence, competence, confidence, likability and willingness to rely on".

A study by [18] also referred that trust directly and indirectly affects a consumer's purchase decision in combination with perceived risk and perceived benefit. Besides, trust has been found to have longer term influence on the relationship in the future (i.e., e-loyalty) through satisfaction, an important outcome of the buying process. This mean that, trust affect customer's direct purchase decision as well as the longer-term relationship.

\section{F. Interest}

A number of researchers have found that interest commercials induce more positive affective reactions to customers than non-interest commercials. In the research by [19], the researcher noted that "Interest involves having some personal feelings about the products and brands being displayed. Whether or not buying is the final outcome, interest simple measure a person's liking for being around the auto 
show." In details, when audiences interested in an advertisings, they will want to watch that advertisings over and over again, then it will positively impact the feeling of customers toward brands and products have been advertised.

As [20] has generally defined a person's interests as: the books they like, the political figures they follows, the activities they participate in, the goods they consume and enjoy, etc. The researcher found out the direct and causal relationship between consumers' interests and their consumption behaviors. Consumers, who usually have a limited budget, have to make consumption choices based on a daily basis. Additionally, consumption choices are determined by preferences, and preferences are coming from consumer's interest. Base on this reason, the link between consumer interest and consumption choices was clearly demonstrated.

More recently, [21] investigated about the influence of mobile marketing as a communication tools on generating consumers' purchase intention. The result stated that five factors of mobile advertising (Interest, Individual attention, Impact, Problem faced and Disturbance at work) have significantly impact on purchase decision of the consumers. From this study, consumer's interest was determined as most significant factor affect to their purchase intention.

\section{G. Brand Awareness}

Brand awareness is associated to the strength of the brand node or trace in memory, which we can measure as the consumers' ability to identify the brand under different condition [22].

Creating and maintaining brand awareness is considered as one of the most main goals of marketing [23]. Brand awareness strengthens the present of brand in consumer's mind [24] and it is a component of the quantity of brand-related exposures and encounters collected by the customer. Excellent book of [25] also defined brand awareness as "The extent and ease with which customers recall and recognize the brand and can identify the products and services with which it is associated."

Brand recall associated with consumer's ability to recover the brand when set of products were given. A cue was set by satisfied the need with the category product, or other type of test. As such, brand was correctly created from customers' memory by brand recall [26].

Brand recognition related to “consumers' ability to confirm prior exposure of a given cue." This implies that, after saw or heard the brand, the customer can accurately distinguish it with other brand. When customers decide which brand to buy, brand recognition plays the role of particular essential key in buying-decision [26].

\section{H. Customers' Loyalty}

Consumer loyalty is consumer repeating purchase intention to some specific products on services in the future. The customer loyalty is categorized by building up and keeping up the associations with the customers, a higher volume and value of purchasing, resistance at higher prices; introduce to others and ignore competitive product [27].

Recently, more researchers have investigated about overall effect on the advertising industry or macro perspective of advertisement on customer's loyalty. Reference [28] inspected that, the effect of increased advertising exposures on consumers loyal to the brand and whether it affect to market share and brand purchase. Once brand A have rate over of $50 \%$, the consumers who buy it were classified with highly loyalty. That demonstrated that when brand advertised more, the patronage customers will purchase it more. Result indicated that advertisement effectiveness was differed from customer loyalty. When advertising for regularly purchased product categorize increased, consumers of high loyalty will purchase these product and brand more.

In 1998, [29] examined the effect of advisement exposure on brand loyalty and brand purchase. The results exposed that the most determination factors of buying behavior were brand loyalty, not advertising. Advertising is effectively increased the quantity of purchase, but not fascinated new customers. Furthermore, brand loyalty was found as a noteworthy representative of advertising exposures impact. For the product with more loyal customers, the respond to advertising exposures much stronger.

With the mentioned above independent and dependent variables related to the customers' loyalty, this study hypothesizes that:

$\mathbf{H}_{1}$ : Factors of TVCs positively affects Customers' Brand Recall.

$\mathbf{H}_{2}$ : Factors of TVCs positively affects Customers' Brand Recognition.

$\mathbf{H}_{3}$ : Factors of TVCs and Brand Awareness positively affect Customer's loyalty

$\mathbf{H}_{4}$ : The effects of TVCs on Customers' Loyalty are mediated by Brand Recall.

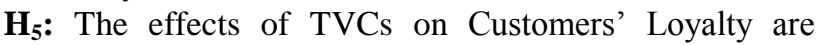
mediated by Brand Recall.

\section{MethodOLOGY}

\section{A. Questionnaire Design and Data Collection}

The purpose of this research was investigating the effect of television commercials of milk products on consumers' loyalty; the quantitative approach was applied as the main method of this study. Moreover, based on the objectives of this study, its exploratory and descriptive nature, a survey was considered the most applicable data collection method.

The target population of this study involves milk's customers of Anlene, Vinamilk fresh milk, Dutch Lady Complete, Dumex, Dielac Optimum and Dutch Lady fresh milk. Since the exact number of the total population is unknown, a sample of this study was selected through the convenience sampling method.

A structured questionnaire was designed basing on major concepts and variables drawn from literature. The questionnaires were conveniently and directly delivered 300 customers at different public places such as supermarkets, offices, milk products stores, and households in Ho Chi Minh City.

\section{B. Factor Analysis and Reliability}

Two exploratory factor analyses were conducted separately for 31 items of seven independent factors and 15 items of 
three dependent factors using Varimax rotation method with the application of Kaiser-Meyer-Olkin measure (KMO) and Barltlett's test of sphericity. The Kaiser-Meyer-Olkin Measure of Sampling Adequacy was .891 for the group of dependent variables and .898 for the group of independent variables (according to Pallant [30] to be significant, the value has to be .60 or above), indicating that the present data was suitable for principal components analysis. Similarly, Bartlett's test of sphericity [31] was significant $(p<0.001)$, indicating sufficient correlation between the variables to proceed with the analysis.

As the results of the two factor analyses, 14 items of three dependent variables and 27 items of seven independent variables were remained. The group of three dependent factors accounted for 58.5 percent of the total variance with the Cronbach's coefficients ranged from .785 to .797 among these factors, indicating a very good internal consistency of these three factors.

TABLE I: SUMMARY OF DEPENDENT VARIABLES WITH RELIABILITY COEFFICIENTS

\begin{tabular}{lcc}
\hline \hline Given Names & Number of Items & Alpha \\
\hline 1. Brand Recall (BRARECA) & 5 & .797 \\
2. Brand Recognition (BRARECO) & 4 & .796 \\
3. Customers' Loyalty (CUSLOY) & 5 & .785 \\
\hline \hline
\end{tabular}

The group of seven independent factors accounted for 64.3 percent of the total variance with the Cronbach's coefficients ranged from .725 to .843 among these factors showing good subscale reliability as can be seen in Table II.

TABLE II: SUMMARY OF INDEPENDENT VARIABLES WITH RELIABILITY COEFFICIENTS

\begin{tabular}{lcc}
\hline \hline Given Names & $\begin{array}{c}\text { Number of } \\
\text { Items }\end{array}$ & Alpha \\
\hline 1. Music of TVCs (MUSIC) & 4 & .775 \\
2. Trust toward TVCs (TRUST) & 4 & .843 \\
3. Humor of TVCs (HUMOR) & 4 & .786 \\
4. Interest of TVCs (INTER) & 3 & .748 \\
5. Advertising Message of TVCs (ADMES) & 4 & .789 \\
6. Repetition of TVCs (REPET) & 5 & .771 \\
7. Length of TVCs (LENGTH) & 3 & .725 \\
\hline \hline
\end{tabular}

\section{RESULTS}

\section{A. Profile of Consumers Involved in the Study}

The profiles of consumers involved in the study are shown in Table III.

\section{B. Correlations between Factors of TVC and Purchase Intention}

The Table IV showed the results of the Pearson's Correlation tested in order to measure the strength and direction of association that exist between factors of TVCs, Brand Recall, Brand Recognition and Customers' Loyalty. The finding indicated the positive correlations between nine independent variables (TRUST, REPET, MUSIC, HUMOR, ADMES, INTER, LENGTH, BRARECA, BRARECO and RECALL) and the dependent variable (CUSLOY) at $p<.01$. Among these relationships, there was a strongest positive correlation between BRARECO and CUSLOY ( $r=.500$, $p<.01)$. This means that a high level of Trust, Repetition, Music, Humor, Advertising Messages, Interest, Length, Brand Recall Brand Recognition are associated with the high level of Consumers' Loyalty.

TABLE III: CONSUMERS' PROFILE ( $N=300)$

\begin{tabular}{|c|c|c|c|}
\hline & & Frequency & Percentage \\
\hline \multirow{3}{*}{ Gender } & Male & 67 & 22.3 \\
\hline & Female & 233 & 77.7 \\
\hline & Total & 300 & 100.0 \\
\hline \multirow{3}{*}{$\begin{array}{l}\text { Marital } \\
\text { Status }\end{array}$} & Single & 133 & 44.3 \\
\hline & Married & 166 & 55.3 \\
\hline & Total & 299 & 99.7 \\
\hline \multirow{6}{*}{ Age } & $18-25$ years old & 119 & 39.7 \\
\hline & $26-35$ years old & 73 & 24.3 \\
\hline & $36-45$ years old & 76 & 25.3 \\
\hline & $46-55$ years old & 27 & 9.0 \\
\hline & Above 55 years old & 4 & 1.3 \\
\hline & Total & 299 & 99.7 \\
\hline \multirow{6}{*}{$\begin{array}{c}\text { Educational } \\
\text { Level }\end{array}$} & High School & 85 & 28.3 \\
\hline & Vocational Level & 22 & 7.3 \\
\hline & College & 39 & 13.0 \\
\hline & Graduated & 140 & 46.7 \\
\hline & Master & 13 & 4.3 \\
\hline & Total & 299 & 99.7 \\
\hline \multirow{6}{*}{ Income } & Below 5 million VND & 142 & 47.3 \\
\hline & 5-10 million VND & 85 & 28.3 \\
\hline & 10-15 million VND & 44 & 14.7 \\
\hline & 15-20 million VND & 16 & 5.3 \\
\hline & Above 20 million VND & 10 & 3.3 \\
\hline & Total & 299 & 99.0 \\
\hline
\end{tabular}

TABLE IV: DESCRIPTION AND VARIABLES' CORRELATIONS

\begin{tabular}{lccccccccc}
\hline & CUSLOY & $\mathbf{1}$ & $\mathbf{2}$ & $\mathbf{3}$ & $\mathbf{4}$ & $\mathbf{5}$ & $\mathbf{6}$ & $\mathbf{7}$ & $\mathbf{8}$ \\
\hline 1. TRUST & $.472^{* *}$ & 1 & & & & & & \\
2. REPET & $.418^{* *}$ & $.410^{* *}$ & 1 & & & & & & \\
3. MUSIC & $.247^{* *}$ & $.284^{* *} .304^{* *}$ & 1 & & & & & \\
4. HUMOR & $.211^{* *}$ & $.229^{* *} .349^{* *} .515^{* *}$ & 1 & & & & \\
5. ADMES & $.433^{* *}$ & $.515^{* *} .540^{* *} .436^{* *} .445^{* *}$ & 1 & & & \\
6. INTER & $.446^{* *}$ & $.506^{* *} .545^{* *} .398^{* *} .393^{* *} .591^{* *}$ & 1 & & \\
7. LENGTH & $.310^{* *}$ & $.301^{* *} .487^{* *} .273^{* *} .412^{* *} .458^{* *} .455^{* *}$ & 1 & \\
8. BRARECA & $.479^{* *}$ & $.319^{* *} .471^{* *} .393^{* *} .457^{* *} .539^{* *} .416^{* *} .387^{* *}$ & 1 \\
9. BRARECO & $.500^{* *}$ & $.513^{* *} .426^{* *} .367^{* *} .367^{* *} .596^{* *} .425^{* *} .362^{* *} .645^{* * *}$ \\
\hline Mean & 3.41 & 3.27 & 3.35 & 3.92 & 3.95 & 3.59 & 3.41 & 3.65 & 3.84 \\
Std. Deviation & .687 & .777 & .664 & .714 & .668 & .706 & .726 & .694 & .606 \\
\hline \hline \multicolumn{7}{c}{$* *$ Correlation is significant at the 0.01 level (1-tailed). } &
\end{tabular}

\section{Direct Effects on Customers' Loyalty}

To identify which of the independent factors directly affects customers' loyalty, a multiple regression analysis was employed. According to the result of coefficients between each independent variable and customers' loyalty, the four out of nine independent variables of this research had direct effect on customers' loyalty (CUSLOY): BRARECA ( $B=.274$, $p<.01)$ produced the strongest direct effect on the CUSLOY, followed by TRUST $(B=.194, p<.01)$, BRARECO $(B=.165$, $p<.01)$ and INTER $(B=.145, p<.01)$. These findings indicated that the factors of brand recall, trust, brand recognition and interest had significant and positive effects on customers' loyalty.

\section{Indirect Effects on Customers' Loyalty}

The indirect effect of an independent variable on the dependent variable through the intervening variable was the total product of the effects of that independent variable on the intervening variables and the effect of the intervening variable on the dependent variable [32]. From the result of multiple regression analysis, it was significantly noted that brand recall 
and brand recognition provided moderate positive effect on customers' loyalty with $(B=.274, p<.01)$ and $(B=.165, p<.01)$ respectively.

Besides, the result of multiple regression analysis showed that the brand recall was significantly affected by three factors: Repetition $(B=.175)$, Humor $(B=.171)$ and Advertising Message $(B=.236)$ with significant (Sig.) value <.01. These three independent factors directly affected the mediating variable of brand recall, and then brand recall directly affected customers' loyalty with $(B=.274, p<.01)$. That's why, through mediating variable of brand recall, the factor of repetition, humor, and advertising message indirectly affected customers' loyalty at (.048), (.047), and (.065) respectively. Thus this study suggested that as a high level of repetition, humor, and advertising message become apparent, the brand recognition and customers' loyalty are likely to be greater.

Moreover, the results also showed that brand recognition was mainly affected by two important factors: advertising message $(B=.345, p<.01)$ and trust $(B=.239, p<.01)$. These two factors directly affected the intervening variable of brand recognition and then brand recognition directly caused an effect on customers' loyalty with $(B=.165, \quad p<.01)$. Consequently, through the intervening variable of brand recognition, the factors of advertising messages and trust created indirect effects on customer loyalty at (.057), and (.039) respectively. Therefore this study argued that better advertising messages and trust of television commercials will lead better brand recall and higher level of customers' loyalty.

\section{E. Path Diagram of Customers' Loyalty}

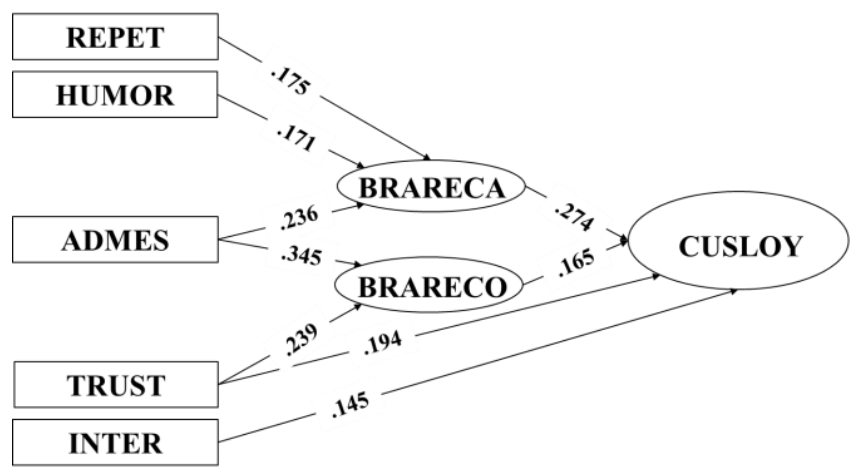

Note: All coefficients were significant at the .005 level.

Fig. 1. Path diagram of CUSLOY model with significant effect coefficients.

\section{F. Significance of the Indirect Effects}

Table $\mathrm{V}$ shows the results of the bootstrapping method recommended by [32] to test the significance of indirect effects or mediations. The output provided the bootstrapped confidence intervals (at the 95\%). If there is a ZERO (0) lies within the interval range between the lower boundary (LL) and the upper boundary (UL), then we can conclude that, with $95 \%$ confidence, there is no mediation or indirect effect. On the other hand, if zero does not occur between the LL and the UL, then we can conclude that, with $95 \%$ confidence, the mediation or indirect effect is significant [33]. As can be seen in the output of Table $\mathrm{V}$, the indirect effects of REPET, HUMOR, and ADMES on CUSLOY through the mediation of BRARECA were estimated to lie between .0183 (LL) and .0850 (UL); .0187 (LL) and .0824 (UL); and .0294 (LL) and 1068 (UL) with $95 \%$ confidence, respectively. In addition, the indirect effects of ADMES and TRUST on CUSLOY through the mediation of BRARECO were estimated to lie between .0170 (LL) and .1028 (UL) and .0116 (LL) and .0715 (UL) with $95 \%$ confidence, respectively. Because zero is not in the $95 \%$ confidence interval, we can conclude that the indirect effects of REPET, HUMOR, ADMES, and TRUST on CUSLOY were indeed significantly different from zero at $p<.05$ (two tailed) and the mediations of BRARECA and BRARECO in this study were true.

TABLE V: DIRECT AND INDIRECT EFFECTS

\begin{tabular}{lccccc}
\hline \hline \multirow{2}{*}{ Variables } & \multicolumn{3}{c}{ Causal Effects } & \multirow{2}{*}{ LL } & \multirow{2}{*}{ UL } \\
\cline { 2 - 5 } & Direct & Indirect & Total & & \\
\hline TRUST & .194 & .039 & .233 & .0116 & .0715 \\
REPET & - & .048 & .048 & .0183 & .0850 \\
HUMOR & - & .047 & .047 & .0187 & .0824 \\
& BRARECA & .065 & .065 & .0294 & .1068 \\
\cline { 2 - 5 } ADMES & BRARECO & .057 & .057 & .0170 & .1028 \\
INTER & .145 & - & .145 & & \\
BRARECA & .274 & - & .274 & & \\
BRARECO & .165 & - & .165 & & \\
\hline TOTAL & $\mathbf{. 7 7 8}$ & $\mathbf{. 2 5 6}$ & $\mathbf{1 . 0 3 4}$ & & \\
\hline \hline
\end{tabular}

The total effects of independent variables impact on customers' loyalty are 1.034, in which direct effects coming from BRARECA, BRARECO, TRUST, and INTER accounted for $75.2 \%$. Indirect effects from ADMES, REPET, HUMOR, and TRUST accounted for $24.8 \%$.

\section{DISCUSSIONS}

The finding of this research demonstrated that customers' trust toward the info of television commercials directly impact on Customers' Loyalty. The result has been supported by [18], which show that trust has a longer term impact on consumer e-loyalty through consumers' satisfaction. Besides, this research has demonstrated the relationship between Trust and Brand Recognition and Trust has indirect impact on Customer's Loyalty. In particular, trust is an important factor effecting customer's loyalty directly. In other way, trust was significant associated with customers' loyalty through Brand Recognition. Moreover, in business, trust toward television advertising can increase the loyal of customers. Advertising has to have meaningful and reliable content that leads customer to belief. The more customers trust in the TVCs' content, the more loyalty they have.

Next is about Brand Recall and Brand Recognition, these factor seem to have the strongest direct effects on Customers' Loyalty. This has been proved in previous researches by [34] and [35], all these authors confirmed that customers' loyalty can be significantly predicted by brand awareness (both brand recall and brand recognition).

The results of this study also indicated the direct link between Interest of TVCs and Customers' Loyalty. This was related to the research by [20] in 2012. They have revealed a direct relationship between customers' buying behavior and their interest. When the customers interested in the television advertisings, they will interested and concentrated more on the advertised brand, then consumption behaviors were driven 
by consumers' interest for that ads.

According to [28] and [29], the increased of advertising exposure have positively impact on customer loyalty for popular product. Recently, the research of [11] in the Telecommunications industry also found out the same result for repetition of advertisement. And that conclusion were on more time confirmed in this study with high rate (3.35) in descriptive analysis and quite high score in Multiple regression Repetition $(B=.048, p<.01)$. The reason can be that the more repetition of ads build positive image of the detergent powder brand in the mind of viewers, because viewers can think that the company which brand is commercialize on TV and repeating again and again will be the largest company.

The other result of this study showed that Humor of TVCs had significant effect on Customers' Loyalty. This result was the supported by the work of [13]. And in the research of [11], humorous nature of the advertisements was the second factor that influences customer patronage. This research also pointed out that through the Brand Recall; Humor of TVCs also has the indirect influence on Customers' Loyalty.

According to the study of [11], message content of the service provider's advertising has showed as the most significant factor influenced customers' loyalty. In this study, Advertising Message not only impact on Customers' Loyalty but also impact on Brand Awareness. The results showed the association between Advertising Message and Brand Awareness (both Brand Recall and Brand Recognition). Through Brand Recall and Brand Recognition, Advertising Message of TVCs has the indirect effect on Customers' Loyalty.

\section{CONCLUSION}

In the following sections, the implications of the research findings of television commercials on customers' loyalty are addressed. In addition, this section also identifies some limitations of current study and proposes some suggestions for future research. This study contributed to an overall understanding of effect of television commercials on customers' loyalty in Ho Chi Minh City by examining the moderating effects of brand awareness. This study measures direct and indirect effects of independent variables (music, trust, humor, interest, advertising message, repetition and length) on dependent variables of customers' loyalty through brand awareness. This study also recommends that advertising manager should improve television advertisings to induce brand awareness as well as brand loyalty.

The practical implications to be drawn from this study have to do with the way in which marketing managers of the milk products like Anlene, Vinamilk, Dutch Lady, Dumex and Dielac should advertisement in the future. To begin with, the findings of this study, based on significant correlations between the independent and dependent variables, suggest that in order to increase Customers' Loyalty, the Companies should follows some recommendations. First, focus on television advertising which is still a most popular channel with the largest audiences. Second, pay attention to the content of television commercials especially with Advertising
Message, Humor, Trust, Interest and Repetition of each advertising to create it more meaningful, truthful, humorous, or interesting. Third, concentrate on the music and humor of TV ad, which were the highly agreement degree from customers. Fourth, interpret the Brand Awareness (as Brand Recall and Brand Recognition.), as factors well predicting Customers' Loyalty.

The results of this study also showed that there were significant relationships between brand recall and independent variables. Accordingly, in order to have high brand recall in brand awareness, this study suggests that marketing manager of the Companies should pay attention and focus on television commercial. Moreover, marketing manager has to consider the three main factors affecting the brand recall. They are repetition, humor and advertising message. These three factors positively impact on brand recall in brand awareness.

This study also found that the brand recognition was one of considerations factor that marketing managers believe that may lead to customers' loyalty. The results showed there were significant relationships between brand recognition and independent variables. Thus, this study suggests that in order to accomplished brand recognition of product, the organizations should focus on television commercials. Also, marketing manager has to focus on the two main factor affect the brand recognition include trustful and advertising message of television advertising. These two factors have a significant effect on brand recognition of product in brand awareness of customers as well as customers' loyalty.

As a final point, with a specific end goal to achieve a high level of customers' loyalty, the marketing managers ought to give careful consideration and attention to the essential elements that give fundamentally contributions to forecasting customers' loyalty directly and indirectly, as resulted by this study. The television commercial should be the priority concern of marketing manager. Likewise, as the study demonstrated that brand recall and brand recognition of product were the main characteristics that milk product like Anlene, Vinamilk, Dutch Lady, Dumex and Dielac and that the television commercial directly affected customers' choice of being loyal.

The finding should be interpreted with caution because some limitations were concerned in this study. First, this research may not cover the effects of all factors of television commercials on customers' loyalty. So subsequent researcher may consider whether any other factor of television commercials would have effect on customer's loyalty, future research may also consider other antecedents of loyalty, such as commitment and relational orientation. Second, future research might update the source of information, also spend time for review more literature to increase the valuable of research findings. Finally, future work should consider the different research method like qualitative with personal interview, so the answers of each consumer will be explained and analyzed in depth.

\section{REFERENCES}

[1] J. Barnard. (December 2014). Executive summary: Advertising expenditure forecasts December 2014. Zenith Optimedia. [Online]. Available: 
http://www.zenithoptimedia.com/wp-content/uploads/2014/12/Adspe nd-forecasts-December-2014-executive-summary.pdf

[2] Advertising spending in Vietnam from 2008 to 2015, by Medium (in million U.S. dollars). (Febuary 2013). Statista. [Online]. Available: http://www.statista.com/statistics/257580/advertising-spending-in-vie tnam-by-medium/

[3] TV advertising still dominates market. (January 15, 2013). Vietnamnet. [Online].

Available: http://english.vietnamnet.vn/fms/business/56998/tv-advertising-still-d ominates-market.html

[4] TV advertising still dominates local market. (January 09, 2014). Vietnamnet. [Online]. Available: http://english.vietnamnet.vn/fms/business/93202/tv-advertising-still-d ominates-local-market.html

[5] N. Hoeberichts, "Music and advertising: The effect of music in television commercials on consumer attitudes," 2012.

[6] T. H. A. Bijmolt, W. Claassen, and B. Brus, "Children's understanding of TV advertising: Effect of age, gender, and parental influence," Journal of Consumer Policy, vol. 21, pp. 171-194, 1998.

[7] F. Schellenberg, "Different types of television commercials," 2011.

[8] R. Batra and M. L. Ray, "Situational effects of advertising repetition: The moderating influence of motivation," Journal Of Consumer Research, vol. 12, no. 4, pp. 432-445, 1986.

[9] L. W. Turley and J. R. Shannon, "The impact and effectiveness of advertisements in a sports arena," Journal Of Services Marketing, vol. 14 , no. 4, pp. 323-336, 2000.

[10] M. Sohail and R. Sana, "The impact of television advertisement repetition, celebrity endorsement and perceived quality on consumer purchase decision," Australian Journal of Basic and Applied Sciences, vol. 5, no. 12, pp. 3044-3051, 2011.

[11] P. Kofi and K. A. Mark, "The influence of advertisement on customer loyalty in the telecommunications industry in Ghana: A case study of kumasi metropolis," Journal of Marketing and Business Management, vol. 3, no. 1, pp. 22-33, 2014.

[12] M. G. Weinberger and C. S. Gulas, "The impact of humor in advertising: A review," Journal of Advertising, vol. 21, no. 4, pp. $35-39,1992$.

[13] C. Hwiman and X. S. Zhao, "Humour effect on memory and attitude: Moderating Role of Product Involvement," International Journal Advertising, vol. 22, no. 1, pp. 117-144, 2003.

[14] B. Mueller, "Reflections of culture: An analysis of Japanese and American advertising appeals," Journal of Advertising Research, vol. 27, no. 3, pp. 51-59, 1987.

[15] D. Maheswaran and J. Meyers-Levy, "The influence of message framing and issue involvement," Journal of Marketing Research, vol. 27, no. 3, pp. 361-367, 1990.

[16] D. H. McKnight and N. L. Chervany, "What trust means in e-commerce customer relationships: An interdisciplinary conceptual typology," International Journal of Electronic Commerce, vol. 6, no. 2 , pp. 35-59, 2001-2002.

[17] H. Soh, L. N. Reid, and K. W. King, "Measuring trust in advertising," Journal of Advertising, vol. 38, no. 2, pp. 83-104, 2009.

[18] J. K. Dan, L. F. Donald, and H. R. Rao, "Trust and satisfaction, two stepping stones for successful e-commerce relationships: A longitudinal exploration," Information Systems Research, vol. 20, no. 2, pp. 237-257, 2009.

[19] Z. H. Nasim, "Measuring the purchase intention of visitors to the auto show," Journal of Management and Marketing Research, pp. 1-17, 2011.

[20] Y. Ercan and D. Kelly, "An interest-based approach for content personalization," 2012.

[21] N. Karthikeyan, "Mobile marketing: Examining the impact of interest, individual attention, Problem faced and consumer's attitude on intention to purchase," Interdisciplinary Journal of Contemporary Research in Business, vol. 3, no. 10, pp. 809-821, 2012.

[22] J. H. Mary and S. Majken, "Taking brand initiative," Jossey-Bass, San Francisco, 2008
[23] E. K. MacDonald and B. M. Sharp, "Brand awareness effects on consumer decision making for a common, repeat purchase product: A replication," Journal of Business Research, vol. 48, pp. 5-15, 2000.

[24] D. Aaker, Building Strong Brands, London: Free Press, 2010.

[25] K. L. Keller, Strategic Brand Management: Building, Measuring and Managing Brand Equity, Pearson Education, Inc, p. 446, 2013.

[26] K. L. Keller, "Conceptualizing, measuring, and managing customer-based brand equity," Journal of Marketing, vol. 57, no. 1, pp. $1-22,1993$.

[27] R. Oliver, "Whence consumer loyalty," Journal of Marketing, vol. 63, pp. 33-44, 1999.

[28] S. Raj, "The effects of advertising on high and low loyalty consumer segments," The Journal of Consumer Research, vol. 9, no. 1, pp. 77-89, 1982.

[29] G. Tellis, "Advertising exposure, loyalty, and brand purchase: A two stage model of choice," Journal of Marketing Research, vol. 25, no. 2 , pp. 134-144, 1998

[30] J. Pallant, SPSS Survival Manual: A Step by Step Guide to Data Analysis Using SPSS, 12th ed., Maidenhead, Berkshire: Open University Press, 2005

[31] M. S. Bartlett, "A note on multiplying factors for various chi-squared approximations," Journal of the Royal Statistical Society, Series, vol. 16, pp. 296-298, 1954

[32] J. K. P. A. A. F. Hayes, "Asymptotic and resampling strategies for assessing and comparing indirect effects in multiple mediator models," in Behavior Research Methods, vol. 40, no. 3, 2008, pp. 879-891.

[33] J. K. P. A. A. F. Hayes, "SPSS and SAS procedures for estimating indirect effects in simple mediationmodels," Behavior Research Methods, Instruments, \& Computers, pp. 717-731, 2004.

[34] M. Dhurup, C. Mafini, and T. Dumasi, "The impact of packaging, price and brand awareness on brand loyalty: Evidence from the paint retailing industry," Acta Commercii, vol. 1, no. 9, 2014.

[35] S. Khan, "Contribution of brand awareness and brand characteristics towards customer loyalty (A study of milk industry of Peshawar Pakistan)," Journal of Asian Business Strategy, vol. 2, no. 8, pp. 170-176, 2012.

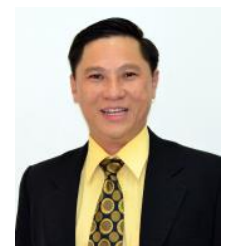

Mai Ngoc Khuong is a lecturer and researcher of School of Business, International University, VNU-HCM. He has a bachelor degree in tourism and hospitality management, master of science degree in leisure, tourism and environment at Wageningen University, the Netherlands, and $\mathrm{PhD}$ degree in development management at School of Public Administration of National Institute of Development Administration (NIDA), Bangkok, Thailand.

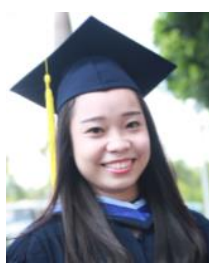

Nguyen Vu Ai Hoa is a research assistant of School of Business Administration- International University, Vietnam National University, Ho Chi Minh. Ms. Hoa has a bachelor degree in business management. Her research interest is consumer behaviour.

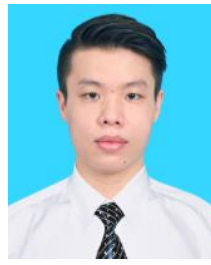

Truong Duc Nguyen is a research assistant of School of Business Administration- International University, Vietnam National University, Ho Chi Minh. Mr Nguyen has a bachelor degree in marketing management. His research interest is consumer behaviour. 